\title{
XXVII. On the asymmetrical action of an alternating current on a polarizable electrode
}

\author{
P.G. Gundry Ph.D. B.Sc. Assoc. R.C.Sc.
}

To cite this article: P.G. Gundry Ph.D. B.Sc. Assoc. R.C.Sc. (1906) XXVII. On the asymmetrical action of an alternating current on a polarizable electrode , Philosophical Magazine Series 6, 11:63, 329-353, DOI: $10.1080 / 14786440609463450$

To link to this article: http://dx.doi.org/10.1080/14786440609463450

Published online: 16 Apr 2009.

Submit your article to this journal $₫$

Џ Article views: 2

Q View related articles $\square$ 


\author{
AND \\ JOURNAI, OF SCIENCE.
}

[SIXTH SERIES.]

$M A R C H 1906$.

XXVII. On the Asymmetrical Action of an Alternating Current on a Polarizalle Electrode. By P. G. Gundry, Ph.D. (Gött.), B.Sc. (Lond.), Assoc. R.C.Sc., late Assist. Lecturer and Demonstrator in Physics at University College, Cardiff* .

THE great advance made by Kohlrausch $\uparrow$ in the study of polarization by the use of alternating currents led to an extended series of researches in the subject, of which especially may be mentioned those of Warburg $\ddagger$, E. Neumann $\S$, M. Wien \|, Krüger $\Psi$, and others. In all these investigations (with the exception of E. Neumann's) the so-called initial polarization capacity was considered, and the strength of the alternating current used was kept sufficiently small for this condition to be satisfied. There are, however, cases in which it is well-nigh impossible with measurable currents to keep within these limits, and $\mathrm{E}$. Neumann has considered the effect of an extension beyond initial polarization capacity in the Wheatstone bridge.

From another side, however, in recent years the consideration of the action of an alternating current on a polarizable electrode has come into prominence, namely, in the

* Communicated by Principal E. H. Griffiths, Sc.D., F.R.S. The greater part of this paper forms part of an Inaugural-Dissertation in the University of Göttingen.

† Kohlrausch, Pogg. Ann. cxlviii. p. 443 (1872).

$\ddagger$ Warburg, Wied. Ann. Ixvii. (1899), and earlier papers.

\$ E. Neumann, Wied. Ann. lxvii. p. 500 (1899).

I| M. Wien, Wied. Ann. Iviii. p. 37 (1896), and others.

I F. Kriger, Zeitsch.f. phys. Chemie, xlr. p. 1 (1903).

Phil. Mag. S. 6. Vol. 11. No. 63. Mardh 1906. 
so-called "Electrolytic Coherer." This instrument was introduced by Fessenden* and Schlömilch $\dagger$, the latter of whom made the first penetrating investigation in the subject. Schlömilch, as is well known, found that the current through an electrolytic cell, in which a very fine point of platinum formed the anode, and to which an E.M.F. of several volts was laid, was greatly increased by excitation with electric waves. He found a negative result when the point was a cathode.

The explanation of Fessenden, that this resulted from a warming of the electrolyte in the immediate neighbourhood of the small electrode, was proved untenable. Later experiments (of Rothmund and Lessing) show a coherer and not an anticoherer effect, when the electrolyte (e.g. phosphoric acid and hypophosphorous acid at higher temperatures) has a negative resistance temperature coefficient. The work of Reich $\ddagger$, in which he found a difference when sending a nonoscillating discharge of a Leyden-jar through the cell according to the direction of the discharge, led him to explain the phenomenon as a depolarization effect.

A great addition to the knowledge of the facts was made by Rothmund and Lessing $\S$. In the first place, they showed that the coherer action was even relatively more pronounced when the applied E.M.F. was under that required for decomposition, and that under these circumstances the very small polarization current was increased when the point was a cathode as well as when it was an anode. The effect of the waves was, however, much greater for an anodically polarized point than for a cathodically polarized one. The magnitude of the effect was found to depend in very great measure on the sign and magnitude of the direct-current polarization. It was also shown that the E.M.F. of electric batteries, in which a small point, made of different metals, formed one of the electrodes, was altered by the action of electric waves.

On the theoretical side there is, so far as I know, no satisfactory explanation. The idea of the depolarization set forth by Rothmund and Lessing, by which one phase of the alternating current passes easily from electrolyte to electrode owing to oxidation, the other with difficulty, based on a comparison with the aluminium rectifier, appears to help but little to a clear understanding of the question. A satisfactory

* Fessenden, Elektrotech. Zeitsch. xxiv. pp. 586 \& 1015 (1903).

+ Schlömilch, ibid. xxiv. p. 959 (1903).

† M. Reich, Phys. Zeitschr. v. p. 338 (1904).

$\S$ Rothmund and Lessing, Drude Ann. xv. p. 193 (1904). 
explanation must account for the very marked dependence on the degree of polarization of the electrode.

We know, however, very little indeed of the conditions which prevail in an oxygen- or hydrogen-charged platinum electrode, and the hope of obtaining a satisfactory explanation of the above phenomenon seems remote until this gap in our knowledge is filled.

The object of the present paper is to show that in a polarizable electrode in general (and the results obtained for the simplest of all cases, here treated, are applicable in principle to all polarizable electrodes). so soon as we pass beyond the stage of initial capacity, the alternating current gives rise to an asymmetry, which would appear as a coherer effect analogous to the above. In order that this asymmetry may be sufficient to account for the coherer effect used in practice, certain conditions must hold (afterwards to be developed), which, though not in antagonism with any known fact, and, indeed, corroborated to some extent by what is known of the conditions, must be proved or disproved by a greater experimental material than $I$ am at present able to bring forward. With this reservation, however, I believe that the application to this practical case is not without interest.

The case here considered is that of a mercury electrode. The conditions are much better known than in the case of platinum, and the changes of concentration, taking place as they do, not in the electrode but in the liquid, are easier to follow. Another advantage that mercury offers, is that the electrode can always be set up in a perfectly definite condition, and with comparative ease in a pure state.

The experiments, to be afterwards described, consisted essentially in the sending of an alternating current of frequency varying between $80 \sim$ and $5000 \sim$ per second through an electrolyte between two electrodes, of which one was very small, the other more than a thousand times as large, so that the latter may be considered as unpolarizable in comparison with the former. A galvanometer in the circuit showed that the alternating current, before symmetric, was rendered asymmetric by the passage through the electrolytic cell. In other words, there was superposed on the alternating current a direct current, and the production of this direct current involves the existence of an asymmetry in the E.M.F. of the polarization produced by the alternating current.

This asymmetry seems, however, to be a natural consequence of the osmotic theory of Electromotive Force in general and its application to polarization in particular. According $\mathrm{Z} 2$ 
to this theory we arrive at the Nernst formula for the E.M.F. of polarization:

$$
\mathbf{E}=\frac{\mathbf{R} \theta}{n} \log _{e} \frac{c_{\mathrm{n}}}{c},
$$

where $\mathrm{R}$ is the gas-constant, $\theta$ the absolute temperature, and $n$ the valency of the ion concerned.

$c_{0}$ is the ionic concentration in the neighbourhood of the large electrode (which remains practically unaltered), and $c$ the concentration of $\mathrm{Hg}$ ions in the layer of electrolyte immediately overlying the small electrode.

If now $c$ oscillates symmetrically about a mean value, the logarithm, being an asymmetrical function, changes asymmetrically.

We have

$$
\mathrm{E}=\frac{\mathrm{R} \theta}{n} \log _{e} \frac{c_{\theta}}{c+j \sin m t}
$$

in the direction corresponding to a cathodic polarization. Without the alternating current

$$
\mathbf{E}=\frac{\mathrm{R} \theta}{n} \log \frac{c_{\mathrm{o}}}{c} .
$$

The E.M.F. in this direction will be increased or diminished according as $j \sin m t$ is negative or positive. It follows, however, from the asymmetry of the function, that the increase when $j \sin m t$ is negative has a far greater effect on the polarization (E.M.F.) than the diminution when $j \sin n t$ is positive. This asymmetry falls away naturally when $j$ is so small as compared with $c$ that, in the expansion of the logarithm in series, only the first term need be retained, i. e. in the condition of initial capacity. So soon, however, as this condition is passed, the asymmetry comes into play, and this all the sooner and the more markedly the smaller $c$ is. It follows, therefore, that the mean value of the E.M.F. is not zero, but that a direct current is produced, which flows from the small electrode to the large electrode in the solution. The asymmetry brings with it an effect equivalent to an apparent dilution of the salt in the neighbourhood of the small electrode, even when the mean concentration really remains unaltered (or even when the mean concentration is really increased by the alternating current, as will be shown sometimes to be the case).

Physically worded, this effect arises becanse a dimination from a small initial value of the concentration causes a much 
greater E.M.F. alteration, than the same concentration increase.

So soon as the alternating current ceases to flow, the E.M.F. also instantaneously ceases to exist. There is no after-effect.

The quantitative consideration of this effect requires an hypothesis of the mechanism of polarization, and is intimately bound up with the nature of polarization capacity. In antagonism to what he called the "Ladungsstromtheorie" of Helmholtz, which looks on the action of the alternating current as the charging and discharging of the condenser-like double-layer, Warburg introduced what he called the "Leitungsstromtheorie," which disregards the part played by the double-layer, and recognizes, alone, the changes of ionic concentration which take place in the neighbourhood of the electrode and the diffusion which goes on simultaneously. These two points of view lead to different results, which may be tested by experiment: viz., according to the Helmboltz view, the polarization-capacity is independent of the frequency; according to the Warburg view, it varies as $\frac{1}{\sqrt{\text { Frequency }}}$, while at the same time the phase-alteration is different according to these two theories. Krüger, taking into account both these elements of polarization capacity, has shown that the one or the other predominates, according to the nature of the electrode and the concentration of the electrolyte. In dealing, however, with the asymmetry, it is clear that the Warburg form alone comes into consideration. The double-layer can introduce no asymmetry, and, indeed, the experiments of Krüger show that, in the cases considered, this part of the polarization capacity is small compared with the other.

The method I have here used is as follows:-An alternating current of pure sine form passes through the electrolyte. The resulting changes of concentration follow also an harmonic law, and the asymmetry of the resulting polnrization, calculated by the Nernst formula, gives an E.M.F. in one direction, which causes the observed direct current. It may be objected, that the symmetry of the current and therefore of the concentration changes is disturbed by this very effect. The direct current observed, however, was always a small fraction of the alternating current, and the alteration of the ion-concentration may relatively without error be considered as due to the undisturbed alternating current. Of course a method of successive approximation may be applied; i.e. from the calculation I have made, a nearer approximation of the 
actual concentration changes may be calculated, and so the E.M.F. of asymmetry reckoned once more; but this nearer approximation would make no essential alteration and would add seriously to the complication.

Following, now, the method of Warburg *, we suppose $i_{0} \sin m t$ the alternating current,

$c_{0}$ the $\mathrm{Hg}$-ion concentration in the neighbourhood of the large electrode (practically unaltered),

$c$ the same in the neighbourhood of the small electrode.

$e$ changes, partly through diffusion, and partly through the quantity of $\mathrm{Hg}$-ions brought in and out of solution by the alternating current.

Let $q=$ area of the small electrode,

and $\epsilon=$ the charge of electricity on a gramme-ion.

For the diffusion, we have:

$$
\frac{\partial c}{\partial t}=\kappa \frac{\partial^{2} c}{\partial \tau^{2}}, \quad \cdot \quad \cdot \quad \cdot \quad \cdot \quad \cdot
$$

where $z$ is measured perpendicular to the small electrode (supposed a small plane), and $\kappa$ is the velocity of diffusion.

The boundary conditions are:-

where $z=0$,

$$
\underset{q \in \kappa}{i_{0} \sin m t}=\left(\frac{\partial c}{\partial z}\right)_{z=0} \quad \text {. . . . . . }
$$

and where $z=\infty$,

$$
c=c_{0}
$$

The solution is:

$$
c=c_{0}+\mathrm{B} e^{-z / \zeta} \cos \left(m t-\frac{\tilde{z}}{\zeta}+\phi\right)
$$

where

$$
\zeta=\sqrt{\frac{2 \kappa}{m}}, \quad \phi=\frac{\pi}{4}, \quad \mathrm{~B}=\frac{\zeta i_{0}}{2 q \epsilon \kappa \cdot \sin \phi}=\frac{i_{0}}{q \epsilon \sqrt{\kappa m}} .
$$

Where $z=0$, we have

$$
c=c_{0}+\mathrm{B} \cos \left(m t+\frac{\pi}{4}\right) \text {. . . . }
$$

The polarization is

$$
\begin{aligned}
p & =\frac{\mathrm{R} \theta}{n} \log _{e} \frac{e}{c_{0}} \\
& =\lambda\left\{\frac{c-c_{0}}{c_{0}}-\frac{1}{2}\left(\frac{c-c_{0}}{c_{0}}\right)^{2}+\frac{1}{3}\left(\frac{c-c_{0}}{c_{0}}\right)^{3}-\ldots\right\},
\end{aligned}
$$

* Warburg, loc. cit. 
Alternating Current on a Polxrizable Electrode. $\quad 335$ where

$$
\begin{aligned}
& \lambda=\frac{\mathrm{R} \theta}{n}=0.0244 \text { volt. } \\
& \frac{c-c_{0}}{c_{0}} \text { is always less than } 1 .
\end{aligned}
$$

The observed direct current I corresponds with an E.M.F. which is the mean value of $p$.

$$
\mathrm{I}=\frac{1}{\mathrm{~W} \cdot \frac{2 \pi}{m}} \int_{0}^{\frac{2 \pi}{m}} p d t, \ldots . \quad . \quad .
$$

where $\mathrm{W}$ is the total resistance in circuit.

Therefore

$$
\begin{gathered}
\mathrm{I}=\frac{\lambda}{\mathrm{W} \cdot \frac{2 \pi}{m}} \int_{0}^{\frac{2 \pi}{m}} d t\left\{\frac{\mathrm{B}}{c_{0}} \cos \left(m t+\frac{\pi}{4}\right)-\frac{1}{2}\left(\frac{\mathrm{B}}{c_{0}}\right)^{2} \cos ^{2}\left(m t+\frac{\pi}{4}\right)\right. \\
+\ldots \ldots\}
\end{gathered}
$$

Now

$$
\begin{aligned}
& \int_{0}^{\frac{2 \pi}{m}} \cos ^{2 p+1}\left(m t+\frac{\pi}{4}\right) d t=0 \\
& \int_{0}^{\frac{2 \pi}{m}} \cos ^{2 p}\left(m t+\frac{\pi}{4}\right) d t=\frac{1}{2^{2 p}} \cdot \frac{2 p(2 p-1) \ldots(p+1)}{p !} \frac{2 \pi}{m}
\end{aligned}
$$

where $p$ is any integer.

Therefore

$$
\begin{aligned}
\mathrm{I}=\frac{\lambda}{\mathrm{W}}\left\{-\frac{1}{2}\left(\frac{\mathrm{B}}{c_{0}}\right)^{2} \frac{1}{2^{2}} \cdot \frac{2}{1}-\frac{1}{4}\left(\frac{\mathrm{B}}{c_{0}}\right)^{4} \frac{1}{2^{4}} \cdot \frac{4.3}{1.2}\right. \\
\left.-\frac{1}{6}\left(\frac{\mathrm{B}}{c_{0}}\right)^{6} \frac{1}{2^{6}} \cdot \frac{6.5 .4}{1.2 .3}-\ldots \ldots\right\} . .
\end{aligned}
$$

This series is convergent if $\frac{\mathrm{B}}{c_{0}}<1$. This condition is always fulfilled, as

$$
\frac{\mathrm{B}}{c_{0}} \cos \left(m t+\frac{\pi}{4}\right)=\frac{c-c_{n}}{c_{0}}<1 .
$$

The series may be summed, but the summation is more easily obtained by direct integration. 
336 Dr. Gundry on the Asymmetrical Action of an

As may easily be shown,

$$
\int_{0}^{2 \pi} \log \left(1+a^{2}+2 a \cos \theta\right)=0
$$

and therefore

$$
\begin{aligned}
& \int_{0}^{2 \pi} \log (1+k \cos \theta) d \theta=\int_{0}^{2 \pi} \log \left(1+a^{2}+2 a \cos \theta\right) d \theta-2 \pi \log \left(1+a^{2}\right) \\
& =-2 \pi \log \left(1+a^{2}\right) \\
& \text { (where } \left.k=\frac{2 a}{1+a^{2}}\right) \\
& =-2 \pi \log \left(\frac{2}{1+\sqrt{1-k^{2}}}\right) . \\
& I=\frac{\lambda}{2 \pi W} \int_{0}^{2 \pi} \log \left\{1+\frac{B}{c_{0}} \cos \left(\theta+\frac{\pi}{4}\right)\right\} \\
& =-\frac{\lambda}{W} \log _{e}\left(\frac{2}{1+\sqrt{1-\frac{\mathrm{B}^{2}}{c_{0}^{2}}}}\right) \text {. }
\end{aligned}
$$

Taking once more the series $(6)$, and neglecting $\left(\frac{B}{c_{0}}\right)^{4}$ and
gher powers,

$$
\begin{aligned}
I=-\frac{\lambda B^{2}}{4 W c_{0}{ }^{2}} & =-\frac{\lambda}{4 W} \frac{i_{0}{ }^{2}}{q^{2} \epsilon^{2} \kappa m c_{0}{ }^{2}} \\
& =-\frac{\lambda}{8 \pi W q^{2} \varepsilon^{2}\left(\kappa c_{0}{ }^{2}\right)} \frac{i_{0}{ }^{2}}{\mathrm{~N}}
\end{aligned}
$$

where $\quad N=\frac{m}{2 \pi}$ is the frequency.

Therefore

$$
\frac{\mathrm{NI}}{i_{0}{ }^{2}}=\text { const. } \quad . \quad \cdot \quad . \quad \text {. . . }
$$

The direct current therefore flows from the small electrode to the large electrode in the electrolyte, and is directly proportional to the square of the strength of the alternating current, and inversely to the frequency.

It is clear that the direct current is the greater, the smaller the value of $c$ is.

It is to be noted that the effect in this case is not a depolarization, but a virtual increase of the polarization. 


\section{Special treatment of the case of the Solution of a Complex Salt.}

It is necessary to treat of solutions of complex salts separately. The polarization capacity of a mercury electrode has been worked out in this case theoretically and experimentally by Krüger *.

In the case of complex salts there is a third element which comes into play in addition to the double-layer of Helmholtz and the effect connected with diffusion, considered by Warburg. This is due to the fact that the mercury ions are formed from complex ions by dissociation when the current brings ions out of solution, and the mercury ions, when brought into solution, disappear to form complex ions, and these ionic reactions do not take place with infinite velocity.

Krüger considers three limiting cases :-

(1) The concentration of the mercury salt is very small. In this case the double-layer plays the most important part, as the ion quantity supplied by dissociation is small compared with that required to form the double-layer.

(2) The solution is of medium strength. With increase of concentration, the diffusion and dissociation come into im. portance. The influence of diffusion, especially that of the undissociated complex, is the important factor.

(3) The limiting case, where the concentration of the salt is very great. If the velocity of reaction were infinite, the electrode would be unpolarizable. This velocity is, however, even if very great, by no means infinitely great, and for frequencies so high as $1000 \sim$ to $5000 \sim$, probably the velocity of reaction is an important factor.

The three cases are characterized by the theoretical result that the polarization capacity in the first is independent of the frequency, in the second is proportional to $\frac{1}{\sqrt{\bar{N}}}$, and in the third to $\frac{1}{\mathrm{~N}}$. Krüger gives cases in which these three limiting cases are realized or at any rate nearly approached.

In considering the asymmetrical action in the case of complex salts, we may put aside the first limiting case as presenting nothing new, being the same as with typical salts of small concentration.

Also in the second case, it is clear that the corresponding case with the solution of a typical salt is only so far altered, that the diffusion is that of the complex, and not that of the mercury ion. The finiteness of the velocity of reaction has

$$
\text { * Krüger, loc. cit. }
$$


338 Dr. Gundry on the Asymmetrical Action of an

no importance in the case where diffusion plays the chief part; and therefore we may suppose that the mercury ions which come into solution practically all disappear instantaneously in the form of the undissociated complex, and with the same rapidity, the mercury ion: required for the opposite phase of the current (from electrolyte to electrode) are supplied from the complexes.

Let us suppose that the equilibrium in a reaction

$$
\mathrm{Hg}_{x} \mathrm{~A}_{y} \longleftrightarrow x \cdot \mathrm{Hg}^{\bullet}+y \cdot \mathrm{A}^{\prime}
$$

(where $\mathrm{A}^{\prime}$ represents the anion, and $\mathrm{Hg}_{x} \mathrm{~A}_{y}$ the formula of the complex salt) is reached with infinite velocity, and corresponds to a very small mercury ion concentration.

Let $c$ be the mercury ion concentration in the neighbourhood of the small electrode.

$c_{0}$ the same in the neighbourhood of the large electrode.

$v, v_{0}$ the corresponding concentrations of the undissociated complexes.

Then $\quad \nu=\sigma c^{x}, \quad \nu_{0}=\sigma c_{0}{ }^{x}$

by the law of mass action, where $\sigma$ is a large constant. The concentration of the anion is considered constant on account of the presence of an indifferent electrolyte with the same anion.

The equations now become

$$
\frac{\partial v}{\partial t}=\kappa \frac{\partial^{2} v}{\partial v}, \ldots . . . \quad \cdot . .
$$

where $z=0$,

$$
\frac{i_{1} \sin n t}{r}=\eta \in \kappa \frac{\partial v}{\partial \tau}, \quad \text {. . . . . . . }
$$

$$
z=\infty,
$$$$
r=v_{u}
$$

The equation $(2)^{\prime}$ is arrived at by supposing that each ion which comes into the solution disappears, and $x$ such ions correspond to one complex molecule.

As before, we have

$$
p=\frac{\mathrm{R} \theta}{n} \log \frac{c}{c_{0}}=\frac{\mathrm{R} \theta}{n \cdot x} \log \frac{\nu}{v_{0}}=\frac{\lambda}{l^{\prime}} \log \left\{1+\frac{\mathrm{B}^{\prime}}{v_{0}} \cos \left(m t+\frac{\pi}{4}\right)\right\},
$$

where

$$
\mathrm{B}^{\prime}=\frac{i_{0}}{q \epsilon_{i} \cdot \sqrt{\kappa m}} \text {, and } \lambda=\frac{\mathrm{R} \theta}{n} \text {, }
$$

$$
p=\frac{\lambda}{r}\left\{\begin{array}{l}
\mathrm{B}^{\prime} \\
\overline{\nu_{0}}
\end{array} \cos \left(m t+\frac{\pi}{4}\right)-\frac{1}{2}\left(\frac{\mathrm{B}^{\prime}}{\nu_{0}}\right)^{2} \cos ^{2}\left(m t+\frac{\pi}{4}\right)+\ldots\right\} .
$$


Alternating Current on a Polarizable Electrode. 339

The direct current $I$ in the direction from large to small electrode in the electrolyte is

$$
\begin{gathered}
\frac{1}{2 \pi}-\int_{0}^{\frac{2 \pi}{m}} p d t=\frac{\lambda}{\bar{W} \cdot e}\left\{-\frac{1}{2}\left(\frac{\mathrm{B}^{\prime}}{v_{0}}\right) \cdot \frac{1}{2^{2}} \cdot \frac{2}{1}-\frac{1}{4} \cdot\left(\frac{\mathrm{B}^{\prime}}{v_{0}}\right)^{4} \cdot \frac{1}{2^{1}} \cdot \frac{4 \cdot 3}{1.2}-\cdots\right\} \\
\mathrm{I}=\frac{-\lambda \mathrm{B}^{\prime 2}}{4 \mathrm{~W} \cdot \nu_{0}^{2} i},
\end{gathered}
$$

if we neglect $\left(\frac{B^{\prime}}{\nu_{0}}\right)^{4}$ and higher powers,

$$
\begin{gathered}
=\frac{-\lambda i_{0}^{2}}{4 W \cdot \nu_{0}^{2} \eta^{2} \epsilon^{2} x^{3} \kappa m}=\frac{-\lambda}{8 \pi \mathrm{W} \cdot q^{2} \epsilon^{2}{x^{3} \kappa v_{\mathrm{u}}{ }^{2}}^{\mathrm{N}}} ; \\
\therefore \quad \frac{i^{2}}{i_{0}^{2}}=\text { const., . . . . . . . . . }
\end{gathered}
$$

where $\mathrm{N}=\frac{m n}{2 \pi}=$ the frequency.

We are, of course, led to the same relation as before. The magnitude of the effect depends upon the smallness of the concentration of the complex substance.

With the third case, however, there is a marked difference. If the concentration of the mercury salt is very great, the changes of concentration that take place are negligible. If the velocity of reaction were infinite, there would be no effect -indeed, no polarization would be possible. This is, however, not the case; and changes take place in the concentration of the mercury ions, though not of the undissociated part.

Following Krüger, we take the case of a mercury salt $\mathrm{HgA}_{\mathrm{g}}$, which is dissociated in very small quantity, according to the equation

$$
\mathrm{HgA} \rightleftarrows \mathrm{Hg}^{\cdot}+\mathrm{A}^{\prime} . \text {. . . . . }
$$

If, now, $c$ is the concentration of the $\mathrm{Hg}$ ions and $c^{\prime}$ that of the undissociated part, then we have the equation of chemical kinetics :

$$
-\frac{d c}{d t}=k_{1} c^{2}-k_{2} c^{\prime}, \ldots . \quad . \quad . \quad . \quad .
$$

where $k_{1}, k_{2}$ are the velocities in the two respective directions of the reaction. A certain very thin layer of thickness $\delta x$ is supposed, in which the polarization phenomena take place.

The quantity of $\mathrm{Hg}$ ion which is brought into the solution by the alternating current in every moment must be equal to that which disappears according to the equation (9). 
340 - Dr. Gundry on the Asymmetrical Aetion of an

In this way, Krüger obtains the formula for the polarization:

$$
p=\frac{R \theta}{2 n} \cdot \log _{e}\left(1+\frac{i_{0}}{\epsilon_{\eta} \cdot \delta_{r} \cdot k_{1} c_{v}{ }^{2}} \sin m t\right),
$$

where $i_{0} \sin m t$ is the alternating current,

I the area of the electrode,

$\epsilon$ the electric charge on a gramme-ion,

and $c_{0}$ the concentration of the $\mathrm{Hg}$ ions in the neighbourhood of the large electrode.

The asymmetry of the logarithm gives rise, once more, to a mean E.M.E., corresponding to a direct current :

$$
\mathrm{I}=-\frac{\mathrm{R} \theta}{2 n \cdot \mathrm{W}}\left\{\frac{1}{2} \mathrm{~K}^{2} \cdot \frac{1}{2^{2}} \cdot \frac{2}{1}+\frac{1}{4} \cdot \mathrm{K}^{4} \cdot \frac{1}{\underline{2}^{4}} \cdot \frac{4.3}{1.2}+\ldots\right\},
$$

where $K=\frac{i_{0}}{\epsilon y \cdot \delta_{1} \cdot k_{1} c_{v}{ }^{2}}$.

The series is convergent, becatise $\mathrm{K}<\mathrm{I}$.

If the alternating current is so weak that the asymmetry just appears, we can neglect $K^{4}, K^{6}$, \&c., and

$$
\frac{\mathrm{I}}{i_{0^{2}}}=-\frac{\mathrm{R} \theta}{\delta n \mathrm{~W}}\left(\frac{1}{\epsilon_{q} \delta \delta_{1} \cdot k_{1} c_{0}{ }^{2}}\right)^{2}=\text { const. . . . }
$$

The direct current is, in this case, independent of the frequency.

\section{Disturbing Effect due to the Asymmetry of the Current itself.}

When the electrolyte was dilute sulphuric acid, it was clear from the experiments that a disturbing effect of a totally different nature was present, and that this masked that previously described. This effect showed itself, nnlike the other, in a permanent increase of the concentration in the neighbourhood of the electrode. There was always an after-effect. When the alternating current ceased to flow, the galvanometer slowly went back to zero.

I attribute this disturbing effect to the following cause. Only a limited number of $\mathrm{Hg}$ ions are at hand to carry the current from electrolyte to electrode. If the number immediately surrounding the electrode does not suffice, it is only by the slow process of diffusion that the defect may be made up. The result is that part of the pulse of the current is carried by hydrogen ions. Before the return pulse of the current from electrode to electrolyte, some of the hydrogen 
has been lost by diffusion. More mercury ions are brought into solution during the one phase of the current than were brought out of it in the other. Hence a real increase of the ionic concentration in the neighbourhood of the small electrode takes place.

It is to be remarked that this effect goes in the opposite direction to the first. Its existence is shown by the presence of an after-effect. Though it is not possible to separate the two effects, it is interesting to note which predominates. I found, with all the electrolytes that I tried, a certain cathodic direct-current polarization, at which the two effects exactly neutralized each other. For lower cathodic polarization (greater $\mathrm{Hg}$-ion concentration) the first effect predominates, and a current flows from small electrode to large in the electrolyte; and for cathodic polarization higher than this "Nullpoint" (i. e. with smaller Hg-ion concentration) the second effect predominates, and the current from the large electrode to the small electrode in the electrolyte is increased by the alternating current. It is clear that both these effects increase as the $\mathrm{Hg}$-ion concentration is diminished, but the second increases more rapidly than the first.

I found the Nullpoint with $\mathrm{H}_{2} \mathrm{SO}_{4}$ saturated with $\mathrm{Hg}_{2} \mathrm{SO}_{4}$ at about 0.14 volt; with $\mathrm{KCN}$, on the other hand, at 0.36 volt; with $K_{2} S$ at about 0.62 volt cathodic directcurrent polarization.

In order to test the results obtained theoretically for the first and more definite effect, it was necessary to use an electrolyte, for which this second effect was inappreciable. Such a case I found to be KCN solution when no directcurrent polarization was applied, as was shown by the very small after-effect on shunting out the alternating current.

That the second effect is unimportant in this case is to be attributed to the fact that here the mercury salt in solution is a complex one, and the excess of $\mathrm{Hg}$ ions brought into solution mostly disappear in the form of complex molecules, and therefore do not to any great extent effect an increase in the $\mathrm{Hg}$-ion concentration. It may also in part be accounted for by the fact that the solation is alkaline owing to hydrolysis, and hence hydrogen ions are present only to a very small extent.

Experiments made with other electrolytes are described fully in another place*. I will here only bring forward the results with this electrolyte, to show to what extent the results previously obtained hold.

* Zeitschr.f. phys. Chemie, liii. p. 177 (1905). 
Apparatus and Experiments.

For the production of the alternating current, I used partly the sine-inductor of Kohlrausch and partly the Dolezalek alternating-current machine, made by Siemens and Halske. In the former, the rotation of a magnet in the form of a small disk inside a coil gives a current of very pure sine form. By use of different weights to drive the clockwork I could obtain currents of frequency $80 \sim$ to $120 \sim$ per sec. With the Dolezalek machine, in which the iron circuit of an electromagnet is almost completed and broken 120 times during each revolution of a wheel and a current induced in a secondary wound round the magnet, a current up to 5000 per sec. $(10,000$ pole changes) could be obtained.

For the measurements of alternating-current strength I used an electrodynamometer of the Kohlrausch type, which gave a double deflexion of $1 \mathrm{~mm}$., read with telescope and scale at a distance of 1 metre, for a current $0.72 \times 10^{-4} \mathrm{amp}$. For alternating currents too small to measure directly I measured the E.M.F. of the machine, using a measurable current and known resistances, and calculated from the resistances in use at any time the current strength.

The direct currents were measured by galvanometers of moving-coil type. In some cases a direct-reading galvanometer of sensitiveness 1 div. for $5 \cdot 5 \times 10^{-7}$ amp. was used, and in others a mirror galvanometer of sensitiveness $1 \mathrm{~mm}$. (double throw) fur $4.32 \times 10^{-9}$ amp.

The electrolyte was contained in a small beaker. A layer of mercury, covering the bottom, formed the large electrode. The electrical connexion with it was made with a platinum wire sealed in a glass tube in the ordinary way.

Dipping in the solution, there was a capillary tube of the form shown in fig. 1 . The small limb, about $3 \mathrm{~cm}$. long, had an inner diameter of $2 \cdot 14 \mathrm{~mm}$. The

Fig. 1.

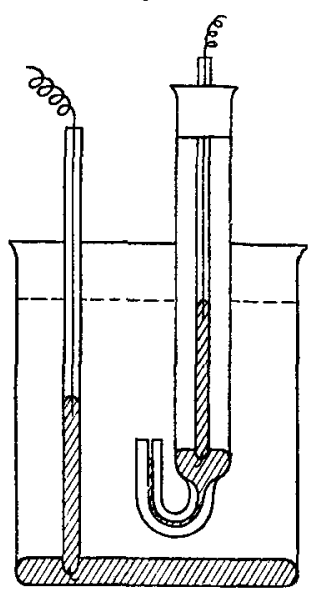
wider limb had a diam. $1 \frac{1}{2} \mathrm{~cm}$. The mercury meniscus was from 2 to $3 \mathrm{~cm}$. from the open end of the tube.

In some experiments the E.M.F. between the electrodes was directly measured with a Dolezalek quadrant electrometer. Its sensitiveness was $1 \mathrm{~mm}$. for 0.0043 volt. 
The arrangement is shown in fig. 2.

Fig. 2.

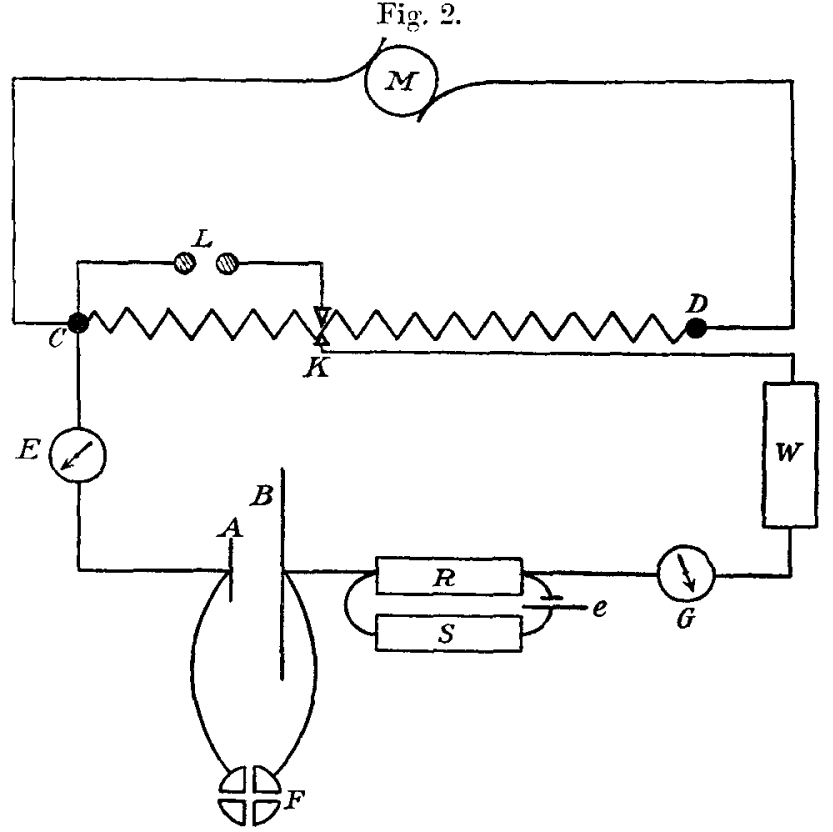

$M$ is the alternating current machine.

E, electrodynamometer.

$\mathrm{AB}$, the solution.

A, the small electrode.

$\mathrm{B}$, the large electrode.

$\mathrm{G}$, the galvanometer.

W, a high resistance.

$\mathrm{R}$ and $\mathrm{S}$ are resistances, and $e$ a battery, so that an E.M.F. $\frac{\mathrm{R}}{\mathrm{R}+\mathrm{S}}$ e could be included in the circuit. $\mathrm{R}+\mathrm{S}$ was always 10,000 ohms.

$\mathrm{F}$, the quadrant electrometer.

CD was a resistance-box which amounted to 11,000 .ohms. The part CK could be 100,200 , \&c. up to 1000 ohms; or 1000,2000 , \&c. up to 11,000 ohms. I could in this way obtain a calculable fraction of the E.M.F. of the machine.

$\mathrm{L}$ was a key, so that the alternating current could be shunted in and out of circuit without stopping the machine.

All the resistances were without self-induction. With higher frequencies the resistance $W$ had a very high value (in most cases $100,000 \mathrm{ohms}$ ), so that the effective increase of the resistance of the galvanometer and electrodynamometer 
344 Dr. Gundry on the Asymmetrical Action of an

due to self-induction could be neglected in comparison with the total resistance.

The experiments, shown in the following tables, were made with normal KCN solution without any direct-current polarization. The direct current observed was always in the direction in the electrolyte from small electrode to large. The deflexions of the galvanometer are shown in the third column. The measurements were made twice for each strength of alternating current, the first series with increasing current and the second with decreasing current; both are given to show the constancy of the effect. In the fourth column the direct current $I$ is obtained from the mean of the two deflexions. In the last column $\frac{\Gamma}{i_{0}{ }^{2}}$ is shown
with the mean of the values given. The value of the external resistance $W$ was $100,000 \mathrm{ohms}$.

TABtie I.

\begin{tabular}{|c|c|c|c|c|c|}
\hline Frequency. & $\begin{array}{c}\text { Altern. } \\
\text { Ourrent. } \\
i_{0} .\end{array}$ & $\begin{array}{c}\text { Galvan. } \\
\text { Defl. }\end{array}$ & $\begin{array}{l}\text { Direct } \\
\text { Ourrent } \\
\quad \text { I. }\end{array}$ & \multicolumn{2}{|c|}{$\frac{I}{i_{0}^{2}}$} \\
\hline 83 & $\begin{array}{c}10-5 \text { amp. } \\
1.3 \\
1.82 \\
2.37\end{array}$ & $\begin{array}{l}22 \cdot 5 ; 22 \cdot 1 \\
36 ; 35 \cdot 8 \\
53 \cdot 2 ; 52 \cdot 6\end{array}$ & $\begin{array}{c}10-8 \text { anp. } \\
19 \cdot 34 \\
31 \cdot 04 \\
45 \cdot 8\end{array}$ & $\left.\begin{array}{r}1144 \\
940 \\
814\end{array}\right\}$ & 966 \\
\hline 181 & $\begin{array}{l}1 \cdot 59 \\
2 \cdot 23 \\
2 \cdot 88 \\
3 \cdot 59\end{array}$ & $\begin{array}{rr}8 \cdot 1 ; & 8 \cdot 2 \\
15 \cdot 0 ; 14 \cdot 1 \\
23 \cdot 3 ; 22 \cdot 6 \\
33 \cdot 9 ; \quad \ldots\end{array}$ & $\begin{array}{r}7 \cdot 06 \\
12 \cdot 56 \\
19 \cdot 84 \\
29 \cdot 24\end{array}$ & $\left.\begin{array}{l}279 \cdot 6 \\
252 \cdot 2 \\
239 \cdot 4 \\
226 \cdot 4\end{array}\right\}$ & $247 \cdot 8$ \\
\hline 288 & $\begin{array}{l}2 \cdot 25 \\
3 \cdot 15 \\
4 \cdot 09 \\
5 \cdot 08\end{array}$ & $\begin{array}{rr}9 \cdot 7 ; & 8 \cdot 2 \\
16 \cdot 8 ; & 15 \cdot 1 \\
26 \cdot 7 & 25 \cdot 7 \\
37 \cdot 8 ; & \cdots\end{array}$ & $\begin{array}{l}7 \cdot 68 \\
13 \cdot 72 \\
22 \cdot 6 \\
32 \cdot 62\end{array}$ & $\left.\begin{array}{c}151.8 \\
138.8 \\
135 \cdot 2 \\
126.8\end{array}\right)$ & $138 \cdot 2$ \\
\hline 442 & $\begin{array}{l}3 \cdot 10 \\
4 \cdot 36 \\
5 \cdot 64 \\
7 \cdot 00\end{array}$ & $\begin{array}{l}10 \cdot 6 ; 9 \cdot 4 \\
17 \cdot 3 ; 17 \cdot 5 \\
28 \cdot 3 ; 28 \cdot 0 \\
41 \cdot 0 ; \quad \ldots\end{array}$ & $\begin{array}{l}8 \cdot 64 \\
15 \cdot 02 \\
24 \cdot 30 \\
35 \cdot 4\end{array}$ & $\left.\begin{array}{l}90 \\
81 \cdot 8 \\
76 \cdot 6 \\
72 \cdot 4\end{array}\right\}$ & $80 \cdot 2$ \\
\hline 587 & $\begin{array}{r}6 \cdot 96 \\
9 \cdot 00 \\
11 \cdot 19\end{array}$ & $\begin{array}{l}18 \cdot 7 ; 17 \cdot 1 \\
28 \cdot 4 ; 28 \cdot 1 \\
40 \cdot 9 ; 40 \cdot 8\end{array}$ & $\begin{array}{l}15 \cdot 46 \\
24 \cdot 30 \\
35 \cdot 26\end{array}$ & $\left.\begin{array}{l}31 \cdot 84 \\
29 \cdot 98 \\
28 \cdot 22\end{array}\right\}$ & $30 \cdot 02$ \\
\hline 1028 & $\begin{array}{r}8 \cdot 70 \\
12 \cdot 18 \\
15 \cdot 77 \\
19 \cdot 6\end{array}$ & $\begin{array}{l}13.8 ; 12.8 \\
24.9 ; 24.5 \\
39.6 ; 39.0 \\
56.6 ; 56.4\end{array}$ & $\begin{array}{l}11 \cdot 50 \\
21 \cdot 30 \\
33 \cdot 98 \\
48 \cdot 8\end{array}$ & $\begin{array}{l}15 \cdot 22 \\
14 \cdot 40 \\
13 \cdot 70 \\
12 \cdot 72\end{array}$ & 14.00 \\
\hline 3100 & $\begin{array}{l}14 \cdot 38 \\
23 \cdot 9 \\
33.5 \\
43 \cdot 4\end{array}$ & $\begin{array}{l}11 \cdot 3 ; \ldots \\
31 \cdot 8 ; 30.2 \\
54 \cdot 5 ; 54.6 \\
80.5 ; 79.8\end{array}$ & $\begin{array}{c}9 \cdot 76 \\
26 \cdot 8 \\
47 \cdot 2 \\
69 \cdot 2\end{array}$ & $\left.\begin{array}{l}4 \cdot 72 \\
4 \cdot 70 \\
4 \cdot 20 \\
3 \cdot 68\end{array}\right]$ & 4.32 \\
\hline
\end{tabular}


Alternating Current on a Polarizable Electrode. $\quad 345$

All these experiments were done directly after one another. Table II. shows the results of another set of experiments, all done together, but on another occasion.

The two sets of results are brought together, and the value of $\frac{\mathrm{NI}}{i_{0}^{2}}$ is given in Table III.

TABLE II.

\begin{tabular}{|c|c|c|c|c|c|}
\hline Frequency. & $\begin{array}{c}\text { Altern. } \\
\text { Current } \\
i_{0} .\end{array}$ & $\begin{array}{c}\text { Galvan. } \\
\text { Defl. }\end{array}$ & $\begin{array}{c}\text { Direct } \\
\text { Current } \\
\text { I. }\end{array}$ & \multicolumn{2}{|c|}{$\frac{\mathrm{I}}{\dot{i_{0}^{2}}}$} \\
\hline 1700 & $\begin{array}{c}10-5 \text { amp. } \\
8 \cdot 63 \\
14 \cdot 31 \\
20 \cdot 1 \\
26 \cdot 0\end{array}$ & $\begin{array}{l}13 \cdot 0 ; 12 \cdot 1 \\
30 \cdot 2 ; 29 \cdot 3 \\
56 \cdot 7 ; 51 \cdot 3 \\
77 \cdot 7 ; \ldots\end{array}$ & $\begin{array}{c}10-8 \mathrm{amp} . \\
10 \cdot 82 \\
25.62 \\
46 \cdot 6 \\
67 \cdot 2\end{array}$ & $\left.\begin{array}{r}14 \cdot 52 \\
12 \cdot 52 \\
11 \cdot 56 \\
9 \cdot 96\end{array}\right\}$ & $12: 14$ \\
\hline 2290 & $\begin{array}{l}18 \cdot 18 \\
25 \cdot 4\end{array}$ & $\begin{array}{l}51 ; 36 \cdot 5 \\
77 \cdot 3 ; 76 \cdot 8\end{array}$ & $\begin{array}{l}3902 \\
66 \cdot 40\end{array}$ & $\left.\begin{array}{l}11 \cdot 84 \\
10 \cdot 30\end{array}\right\}$ & 11.06 \\
\hline 3260 & $\begin{array}{l}15 \cdot 0 \\
25 \cdot 0 \\
34 \cdot 9\end{array}$ & $\begin{array}{l}21 ; 19 \cdot 5 \\
48 \cdot 3 ; 47 \cdot 0 \\
80 \cdot 7 ; 79 \cdot 7\end{array}$ & $\begin{array}{l}17 \cdot 48 \\
41 \cdot 0 \\
69 \cdot 2\end{array}$ & $\begin{array}{l}7 \cdot 76 \\
6 \cdot 56 \\
5 \cdot 68\end{array}$ & 666 \\
\hline 5000 & $\begin{array}{l}21 \cdot 8 \\
28 \cdot 8 \\
36 \cdot 1 \\
50 \cdot 6\end{array}$ & $\begin{array}{r}28 \cdot 2 ; 26 \cdot 7 \\
45.6 ; 43 \cdot 2 \\
63 \cdot 3 ; 63 \cdot 0 \\
1007 ; \quad \ldots\end{array}$ & $\begin{array}{l}23 \cdot 62 \\
38 \cdot 24 \\
54 \cdot 4 \\
80 \cdot 4\end{array}$ & $\begin{array}{l}4 \cdot 96 \\
4 \cdot 60 \\
4 \cdot 18 \\
3 \cdot 14\end{array}$ & $4 \cdot 58$ \\
\hline
\end{tabular}

TABLe III.

\begin{tabular}{|c|c|c|}
\hline $\begin{array}{c}\text { Frequency } \\
\text { N. }\end{array}$ & $\underset{i_{0}}{\mathrm{I}}$. & $\frac{\mathrm{NI}}{i_{4^{2}}^{2}}$. \\
\hline $\begin{array}{r}83 \\
181 \\
288 \\
\mathbf{4 4 2}\end{array}$ & $\begin{array}{l}966 \\
247.8 \\
138 \cdot 2 \\
80.2\end{array}$ & $\begin{array}{l}80200 \\
4800 \\
39800 \\
35+00\end{array}$ \\
\hline $\begin{array}{r}587 \\
1028 \\
3100\end{array}$ & $\begin{array}{r}30.02 \\
14.00 \\
4 \cdot 32\end{array}$ & $\begin{array}{l}17500 \\
14380 \\
13400\end{array}$ \\
\hline $\begin{array}{l}1700 \\
2290 \\
3260 \\
5000\end{array}$ & $\begin{array}{r}12 \cdot 14 \\
11 \cdot 06 \\
6.66 \\
4.58\end{array}$ & $\begin{array}{l}20600 \\
25300 \\
21500 \\
22820\end{array}$ \\
\hline
\end{tabular}

The difference in value for the two sets shows that the condition of the solution is variable. I found in general that results could only be compared when they were obtained on the same day.

Phil. Mag. S. 6. Vol. 11. No. 63. March 1906. 2 A 
346 Dr. Gundry on the Asymmetrieal Action of an

It is seen that only for high frequencies is the relation $\frac{\mathrm{NI}}{i_{0}^{2}}=$ const. in any measure satisfied.

The sudden change in the magnitude of the effect between $\mathrm{N}=400$ and $\mathrm{N}=600$ appeared so striking, that I repeated the measurements on a new solution. The results are shown in Tables IV. and V. In this series of experiments, the resistance $W$ was 30,000 ohms. For the sake of comparison, I have reduced the observed current $I$ to the value $I^{\prime}$ that it would have if the external resistance were $100,000 \mathrm{ohms}$, as in the former experiments.

Table IV.

\begin{tabular}{|c|c|c|c|c|c|c|c|}
\hline Freq. & $\begin{array}{c}\text { Altern. } \\
\text { Current } \\
i_{0^{*}}\end{array}$ & $\begin{array}{c}\text { Direct } \\
\text { Current } \\
\text { I'. }^{\prime} .\end{array}$ & $\frac{I^{\prime}}{i_{0}^{2}}$. & Freq. & $\begin{array}{c}\text { Altern. } \\
\text { Current. } \\
i_{0 .} .\end{array}$ & $\begin{array}{c}\text { Direct } \\
\text { Current } \\
I^{\prime} .\end{array}$ & $\frac{\mathbf{I}^{\prime}}{i_{0}{ }^{2}}$ \\
\hline 332 & $\begin{array}{c}10-4 \text { amp. } \\
0.205 \\
0.304 \\
0.400\end{array}$ & $\begin{array}{c}10-8 \text { amp. } \\
5 \cdot 27 \\
11 \cdot 85 \\
15.9\end{array}$ & $\begin{array}{l}125 \cdot 1 \\
1 \geq 8 \cdot 1 \\
99 \cdot 4\end{array}$ & 1362 & $\begin{array}{c}10-4 \text { amp. } \\
0.563 \\
0.835 \\
1.099\end{array}$ & $\begin{array}{c}10-8 \text { amp. } \\
6.57 \\
14.8 \\
20.6\end{array}$ & $\begin{array}{l}20 \cdot 7 \\
21 \cdot 2 \\
17 \cdot 08\end{array}$ \\
\hline 518 & $\begin{array}{l}0.268 \\
0.398 \\
0.523\end{array}$ & $\begin{array}{r}5 \cdot 75 \\
12 \cdot 4 \\
18 \cdot 26\end{array}$ & $\begin{array}{l}80 \\
78 \cdot 9 \\
66 \cdot 9\end{array}$ & 2000 & $\begin{array}{l}0.689 \\
1.02 \\
1 \cdot 341\end{array}$ & $\begin{array}{l}6 \cdot 91 \\
14 \cdot 35 \\
21 \cdot 4\end{array}$ & $\begin{array}{l}14: 58 \\
13.80 \\
11.92\end{array}$ \\
\hline 523 & $\begin{array}{l}0.319 \\
0.475 \\
0.625\end{array}$ & $\begin{array}{r}5 \cdot 96 \\
12 \cdot 45 \\
18 \cdot 9\end{array}$ & $\begin{array}{l}58 \cdot 6 \\
55 \cdot 2 \\
48 \cdot 4\end{array}$ & 2930 & $\begin{array}{l}0.835 \\
1 \cdot 24 \\
\mathbf{1} \cdot 63\end{array}$ & $\begin{array}{l}7 \cdot 44 \\
17 \cdot 1 \\
24 \cdot 2\end{array}$ & $\begin{array}{c}10 \cdot 67 \\
11 \cdot 1 \\
9 \cdot 12\end{array}$ \\
\hline 758 & $\begin{array}{l}0.399 \\
0.591 \\
0.779\end{array}$ & $\begin{array}{l}6 \cdot 05 \\
13 \cdot 3 \\
19 \cdot 1\end{array}$ & $\begin{array}{l}38 \cdot 0 \\
38 \cdot 1 \\
31 \cdot 6\end{array}$ & & & & \\
\hline 1006 & $\begin{array}{l}0.466 \\
0.692 \\
0.91\end{array}$ & $\begin{array}{l}6 \cdot 48 \\
13 \cdot 8 \\
20 \cdot 2\end{array}$ & $\begin{array}{l}29 \cdot 8 \\
28.8 \\
24 \cdot 4\end{array}$ & 534 & $\begin{array}{l}0.311 \\
0.462 \\
0.608\end{array}$ & $\begin{array}{r}6 \cdot 75 \\
13 \cdot 91 \\
20 \cdot 2\end{array}$ & $\begin{array}{l}70 \\
65 \cdot 4 \\
54 \cdot 7\end{array}$ \\
\hline
\end{tabular}

TABLE V.

\begin{tabular}{|c|c|c|c|}
\hline $\mathrm{N}$. & $\frac{\mathrm{I}}{\bar{i}_{0}{ }^{2}} \cdot$ & $\frac{\mathrm{I}^{\prime}}{i_{0}^{2} \cdot}$ & $\frac{\mathbf{N I}}{\bar{i}_{0}{ }^{2}} \cdot$ \\
\hline 332 & $126 \cdot 6$ & $38 \cdot 0$ & 12600 \\
\hline 518 & $79 \cdot 4$ & $23 \cdot 8$ & 12300 \\
523 & $56 \cdot 9$ & $17 \cdot 08$ & 8940 \\
758 & $38 \cdot 0$ & $11 \cdot 4$ & 8940 \\
1006 & $29 \cdot 3$ & $8 \cdot 8$ & 8810 \\
1362 & $20 \cdot 9$ & $6 \cdot 27$ & 8550 \\
2000 & $14 \cdot 2$ & $4 \cdot 26$ & 8510 \\
2930 & $10 \cdot 9$ & $3 \cdot 27$ & 9550 \\
\hline 534 & $67 \cdot 7$ & $20 \cdot 3$ & 10850 \\
\hline
\end{tabular}


Alternating Current on a Polarizable Electrode. $\quad 347$

There is once more to be noticed a sudden change in the neighbourhood of frequency 500.

The absence of any approach to agreement for lower frequencies may be in part due to the fact that the disturbing effect is of greater importance when the frequency is low than when it is high. For a given value of the alternatingcurrent strength, the lower the frequency the more mercury ions are required for the current. On this account the asymmetry of the current itself may be an important factor. The following tables show the direct current through $100,000 \mathrm{ohms}$ as observed for different values of $i_{0}$ at low frequencies.

TABIJ VI.

TABLE VII.

\begin{tabular}{|c|c|c|c|c|c|}
\hline \multicolumn{3}{|c|}{ Frequeney 89 . } & \multicolumn{3}{|c|}{ Frequency 118.} \\
\hline $\begin{array}{l}\text { Altern. } \\
\text { Current. }\end{array}$ & $\begin{array}{c}\text { Direct } \\
\text { Current. }\end{array}$ & $\frac{1}{i_{i^{2}}^{2}}$ & $\begin{array}{l}\text { Altern. } \\
\text { Current. }\end{array}$ & $\begin{array}{c}\text { Direct } \\
\text { Current. }\end{array}$ & $\frac{\mathrm{I}}{{\overline{i_{0}}}^{2}}$. \\
\hline${ }_{0.93}^{\text {amp. } 10}$ & $\underset{0038}{\text { amp. } 10-5}$ & 4400 & $\operatorname{amp.}_{1.89}$ & $\underset{0.0302}{\operatorname{amp.~} 10-\bar{s}}$ & 846 \\
\hline $1 \cdot 32$ & $0 \cdot 0506$ & 2900 & $2 \cdot 26$ & $0 \cdot 0336$ & 659 \\
\hline $2 \cdot 28$ & 0.0697 & 1340 & $2 \cdot 82$ & $0 \cdot 0451$ & 567 \\
\hline $3 \cdot 01$ & $0 \cdot 0936$ & 1034 & $3 \cdot 74$ & $0 \cdot 0630$ & 450 \\
\hline $4 \cdot 65$ & $0 \cdot 1195$ & 551 & 5.54 & 0.0922 & 302 \\
\hline $5 \cdot 80$ & $0 \cdot 1392$ & 414 & $6 \cdot 47$ & $0 \cdot 1075$ & 257 \\
\hline $8 \cdot 37$ & $0 \cdot 1750$ & 250 & 7.29 & $0 \cdot 1158$ & 218 \\
\hline
\end{tabular}

TABLE VIII.

\begin{tabular}{|c|c|c|}
\hline $\begin{array}{c}\mathrm{N}=93 . \\
\text { Altern. Ourrent. }\end{array}$ & $\begin{array}{c}\text { Direct } \\
\text { Current. }\end{array}$ & $\frac{\mathrm{I}}{i_{0}^{2}}$. \\
\hline $\operatorname{amp.}_{4 \cdot 2}^{10-6}$ & $\underset{3 \cdot 4}{\operatorname{aunp} .10-8}$ & 1950 \\
\hline 467 & $4 \cdot 18$ & 1917 \\
\hline $5 \cdot 25$ & $4 \cdot 45$ & 1615 \\
\hline $6 \cdot 1$ & 571 & 1535 \\
\hline $7 \cdot 0$ & 672 & 1372 \\
\hline 8.4 & 8.05 & 1141 \\
\hline 105 & 1088 & 887 \\
\hline
\end{tabular}

From Tables VI. and VII. it appears that the lower the 2 A 2 
348 Dr. Gundry on the Asymmetrical Action of an frequency the greater is the variation of $\frac{\mathrm{I}}{i_{0}^{2}}$ with $i_{0}$, and Takle VIII. shows that by making the current smaller, the variation is greatly reduced. Were it possible to work with still smaller currents, it may well be that a much nearer approach to constancy of $\frac{\mathrm{I}}{i_{0}{ }^{2}}$ at these low frequencies might
be found. Finally, Table IX. shows a test for an after-effect. A comparatively strong alternating current $\left(3.05 \times 10^{-4} \mathrm{amp}\right.$.) was run for half an hour through the cell, and readings of the galvanometer deflexion were made every 3 minutes. The alternating current was then shunted out and readings taken every $\frac{1}{4}$ minute. There was $40,000 \mathrm{ohms}$ in the circuit.

Table IX.

Frequency 680. Altern. current 3.05 × 10-4 amp.

\begin{tabular}{|c|c|c|c|}
\hline \multirow{2}{*}{$\begin{array}{l}\text { Time. } \\
\text { min. }\end{array}$} & \multicolumn{2}{|c|}{ Readings of Galvanometer. } & \multirow{2}{*}{ Deflexion. } \\
\hline & $\begin{array}{l}\text { Without } \\
\text { Alt. Cur. }\end{array}$ & $\begin{array}{c}\text { With } \\
\text { Alt. Cur. }\end{array}$ & \\
\hline $\mathbf{0}$ & $677 \cdot 3$ & & \\
\hline 3 & $\ldots \ldots$ & $475 \% 5$ & $201 \cdot 8$ \\
\hline 6 & $\ldots \ldots$ & $485^{\circ} 5$ & $181 \cdot 8$ \\
\hline 9 & ...... & $478 \cdot 0$ & $199 \cdot 3$ \\
\hline 12 & $\ldots \ldots$ & $48: 9$ & $194: 4$ \\
\hline 15 & $\ldots \ldots$ & $488 \cdot 7$ & $\mathbf{1 8 8} 6$ \\
\hline 18 & $\ldots \ldots$ & $497 \cdot 6$ & $179 \cdot 7$ \\
\hline $21 .$. & $\ldots \ldots$ & $507 \cdot 0$ & $170 \cdot 3$ \\
\hline $24 \ldots \ldots \ldots$ & $\ldots \ldots$ & $507 \cdot 1$ & $170 \cdot 2$ \\
\hline $27 \ldots \ldots \ldots$ & $\ldots \ldots$ & $513 \cdot 9$ & $163 \cdot 4$ \\
\hline $30 \ldots \ldots \ldots$ & . & $514 \cdot 7$ & 1626 \\
\hline $30 \frac{1}{4} \ldots \ldots \ldots$ & 6625 & $\ldots \ldots$ & $14 \cdot 8$ \\
\hline $36 \frac{1}{2}$. & $672 \cdot 4$ & ....... & $4 \cdot 9$ \\
\hline $30 \frac{3}{4} \ldots \ldots \ldots$ & $675 \cdot 0$ & $\ldots \ldots$ & $2 \cdot 3$ \\
\hline 31 & 6756 & ....... & $1 \cdot 7$ \\
\hline $31_{4}^{1} \ldots$ & $676 \cdot 1$ & $\ldots \ldots$ & $1 \cdot 2$ \\
\hline $31 \frac{1}{2} \ldots$ & $676 \cdot 4$ & $\ldots \ldots$ & 0.9 \\
\hline $31 \frac{3}{4} \ldots \ldots \ldots$ & $675 \cdot 2$ & $\ldots \ldots$ & $2 \cdot 1$ \\
\hline
\end{tabular}

Even after this long subjection to a strong alternating current, very slight after-effect is to be observed.

By using a capillary of wider bore I found the value of $\frac{\mathrm{I}}{i_{0}^{2}}$ to vary inversely as the fourth power of the diameter, which is also in agreement with the theoretical result. 


\section{The Effect with a Gas-charged Platinum Electrode in Sulphuric Acid.}

I was not able to realize with complex salts of mercury the case where the effect, arising from the finiteness of the velocity of reaction, is independent of the frequency. It appears with $\mathrm{KCN}$-solutions, from the approach to constancy of $\frac{\mathrm{NI}}{i_{0}^{2}}$, that the velocity of reaction is sufficiently great for the effect due to diffusion to come first into play, even where the solution is comparatively strongly concentrated.

In a case where an asymmetrical effect is large at a very high frequency-at which diffusion must cease to play an important part-one is led, inversely, to consider that the effect, if it arises at all in the way above described, can only do so through the finiteness of some velocity of reaction. Such a case is that of the ordinary electrolytic coherer-a small gas-charged Pt electrode in dilute sulphuric acid.

In the first place, the effect of the above described asymmetry would be a virtual diminution of the gas charge, i.e. a depolarization such as is observed.

As for evidence of the reaction which takes place, the following work on the solution of hydrogen in palladium and platinum bears on the subject.

Hoitsema * found from the pressure-concentration curve of hydrogen in palladium, that the hydrogen is dissolved at ordinary temperatures in the atomic form and not in the molecular.

A. Winkelmann $\uparrow$ found that hydrogen diffuses through glowing palladium as $\mathrm{H}$, and not as $\mathbf{H}_{2}$.

The same author $\ddagger$ found an exactly analogous result for hydrogen diffusing through hot platinum.

More recently, O. W. Richardson, Nicol, and Parnell $\S$ have shown that the dissociation of the hydrogen takes place in the platinum, and not outside it.

With regard to polarization experiments, it is interesting to note that M. Wien \| found for palladium electrodes, covered with Pd-black and strongly charged with hydrogen,

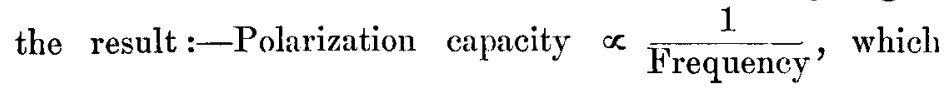

* Hoitsema, Zeitsch.f. phys. Chemie, xvii. p. 1 (1895).

+ A. Winkelmann, Drude Annalen, vi. p. 104 (1901).

$\ddagger$ A. Winkelmann, Drude Annalen, viij. p. 388 (1902).

$\$$ O. W. Richardson, Nicol, and Parnell, Phil. Mag. vii. (1904).

i| M. Wien, Drude Annalen, viii. p. 372 (1902). 
corresponds with finiteness of velocity of reaction as worked out by Krüger. With platinized platinum electrodes charged with hydrogen, and with $\mathrm{Pd}$ electrodes less strongly charged, the result :-

Polarization capacity $\propto \frac{1}{\sqrt{\text { Frequency }}}$, which corresponds with the case of diffusion, was found. The same result was found by Schönherr* for unplatinized Pt electrodes, which were kept charged by an upplied direct-current E.M.F.

'The evidence, therefore, for the reaction $\mathrm{H}_{2}=2 \mathrm{H}$ taking place with finite velocity, and hence giving rise to polarization effects, is affirmative with palladium under certain conditions; but not so with platinum, where the effect corresponding with diffusion seems to hold.

It is, however, to be added that, at higher and higher frequencies the diffusion effect becomes of less and less importance ; and the effect due to the finiteness of velocity of reaction, though smaller than the diffusion effect at lower frequencies, would eventually at sufficiently high frequencies outweigh it.

Under other conditions with unplatinized platinum electrodes, the initial polarization capacity was found independent of the frequency. This, which corresponds with the Helmholtz double-layer, would introduce no asymmetry. It is thus seen that the nature of the initial polarization capacity may be no safe criterion as to the asymmetry that may arise at higher frequencies.

\section{Experiments with a Platinum Electrode.}

I have made experiments with platinum electrodes in 3 norm. solution of sulphuric acid of the same nature as those described with mercury electrodes. The large electrode was a piece of platinized platinum foil about $4 \mathrm{sq} . \mathrm{cm}$. in area. A platinum wire $\frac{1}{10} \mathrm{~mm}$. diameter was sealed in the end of a tube and then cut off flush with the glass. This formed the small electrode.

The arrangement and method were the same as before, except that both cathodic and anodic direct-current polarization were used. In order that the state of polarization of the small electrode might be determined, I measured the potential-difference between it and a third electrode of zinc, which dipped in a second beaker. This beaker was filled

\footnotetext{
* S chönherr, Drude Annalen, vi. p. 116 (1901).
} 
Alternating Current on a Polarizable Electrode. 351 with the same solution as the first, and an electrical connexion was made between the two solutions by means of an inverted U capillary-tube, also filled with the solution. The E.M.F. measurements were made according to the Poggendorf method. The E.M.F. is given in terms of the $\mathrm{H}$ electrode as 0.0 volt.

It was found necessary to polarize the electrode half an hour to an hour long before taking readings in order to obtain regular results. It was also found necessary to keep the alternating current small-otherwise the condition of the electrode appeared to be permanently altered.

The results are shown in Tables $\mathrm{X}$. to XIII.

TABLE X.

Anodic Polarization. E.M.F. of small electrode $1 \cdot 7$ volt.

\begin{tabular}{|c|c|c|c|c|c|c|c|}
\hline Freq. & $\begin{array}{l}\text { Altern. } \\
\text { Current. }\end{array}$ & $\begin{array}{l}\text { Direct } \\
\text { Current. }\end{array}$ & $\begin{array}{c}\mathrm{I} \\
i_{0}{ }^{2}\end{array}$ & Freq. & $\begin{array}{l}\text { Altern. } \\
\text { Current. }\end{array}$ & $\begin{array}{l}\text { Direct, } \\
\text { Current. }\end{array}$ & $\frac{I}{i_{0}^{2}}$ \\
\hline 1391 & $\begin{array}{c}\operatorname{amp.}{ }^{1} 0^{-4} \\
1.81 \\
2.06 \\
2.38\end{array}$ & $\begin{array}{c}\text { amp. } 10^{-7} \text {. } \\
2 \cdot 55 \\
3 \cdot 71 \\
4.82\end{array}$ & $\begin{array}{l}7 \cdot 8 \\
8 \cdot 7 \\
8 \cdot 9\end{array}$ & 2600 & $\begin{array}{c}\operatorname{amp} .10^{-4} \\
2 \cdot 44 \\
201\end{array}$ & $\begin{array}{c}\text { amp. } 10^{-7} \\
2.45 \\
4 \cdot 22\end{array}$ & $\begin{array}{l}4.11 \\
4.99\end{array}$ \\
\hline 1737 & $\frac{2.27}{2.58}$ & $\begin{array}{l}315 \\
458\end{array}$ & $\begin{array}{l}6 \cdot 11 \\
6.9\end{array}$ & 4350 & $\begin{array}{l}2 \cdot 35 \\
308 \\
3 \cdot 88\end{array}$ & $\begin{array}{l}1 \cdot 63 \\
3 \cdot 90 \\
6 \cdot 91\end{array}$ & $\begin{array}{l}2 \cdot 96 \\
4 \cdot 12 \\
4 \cdot 6\end{array}$ \\
\hline 2020 & $\begin{array}{l}2 \cdot 26 \\
2.696\end{array}$ & $\begin{array}{l}268 \\
4 \cdot 24\end{array}$ & $\begin{array}{l}\tilde{3} \cdot 25 \\
600\end{array}$ & 1770 & $\begin{array}{l}232 \\
264\end{array}$ & $\begin{array}{l}3 \cdot 12 \\
4 \cdot 23\end{array}$ & $\begin{array}{l}58 \\
6.07\end{array}$ \\
\hline
\end{tabular}

Table XI.

Anodic Polarization. E.M.F. of small electrode 1:36 volt.

\begin{tabular}{|c|c|c|c|c|c|c|c|}
\hline Freq. & $\begin{array}{l}\text { Altem. } \\
\text { Current. }\end{array}$ & $\begin{array}{l}\text { Direct } \\
\text { Current. }\end{array}$ & $\frac{I}{i_{0}^{2}} \cdot$ & Freq. & $\begin{array}{l}\text { Alterm, } \\
\text { Current. }\end{array}$ & $\begin{array}{l}\text { Direct } \\
\text { Current. }\end{array}$ & $\frac{I}{i_{0}^{* *^{*}}}$ \\
\hline 2070 & $\underset{+41}{\operatorname{amp.} 10^{-4}}$ & $\underset{0 \cdot 10 \pm}{\operatorname{amp} .10^{-7}}$ & 0.0536 & 3550 & $\begin{array}{c}\operatorname{amp.} 10^{-4} \\
\frac{1}{4} 62 \\
53\end{array}$ & $\begin{array}{c}\text { anp. } 10^{-7} \\
0.225 \\
0.606\end{array}$ & $\begin{array}{l}0 \cdot 105 \\
0.216\end{array}$ \\
\hline 2620 & $\begin{array}{l}505 \\
559\end{array}$ & $\begin{array}{l}0.242 \\
0.58\end{array}$ & $\begin{array}{l}0 \cdot 095 \\
0 \cdot 186\end{array}$ & 4040 & 442 & $0 \cdot 156$ & 0.08 \\
\hline 2990 & $\begin{array}{l}511 \\
572\end{array}$ & $\begin{array}{l}0.363 \\
1 \cdot 1\end{array}$ & $\begin{array}{l}0 \cdot 139 \\
0 \cdot 336\end{array}$ & & $\begin{array}{l}5.17 \\
593\end{array}$ & $\begin{array}{l}0501 \\
1.93\end{array}$ & $\begin{array}{l}0.188 \\
0.549\end{array}$ \\
\hline 3340 & $\begin{array}{l}5 \cdot 02 \\
566\end{array}$ & $\begin{array}{l}0 \cdot 277 \\
0 \cdot 783\end{array}$ & $\begin{array}{l}0 \cdot 107 \\
0 \cdot 246\end{array} \mid$ & 2100 & $\begin{array}{l}4.06 \\
449\end{array}$ & $\begin{array}{l}0 \cdot 121 \\
0 \cdot 225\end{array}$ & $\begin{array}{l}0.074 \\
0.115\end{array}$ \\
\hline
\end{tabular}


352 Dr. Gundry on the Asymmetrical Action of an

TABle XII.

Cathodic Polarization. E.M.F. of small electrode $0 \cdot 0$ volt.

\begin{tabular}{|c|c|c|c|c|c|c|c|}
\hline Freq. & $\begin{array}{l}\text { Altern. } \\
\text { Current. }\end{array}$ & $\begin{array}{l}\text { Direct } \\
\text { Current. }\end{array}$ & $\frac{I}{{\overline{i_{0}}}^{2}}$ & Freq. & $\begin{array}{l}\text { Altern. } \\
\text { Current. }\end{array}$ & $\begin{array}{c}\text { Direct } \\
\text { Current. }\end{array}$ & $\frac{I}{i_{0}^{2}}$ \\
\hline 1300 & $\begin{array}{c}\text { axp. } 10^{-4} \\
1 \cdot 93 \\
2 \cdot 18 \\
2 \cdot 44\end{array}$ & \begin{tabular}{|c} 
arup. $10^{-7}$ \\
$1 \cdot 29$ \\
$2 \cdot 2$ \\
$2 \cdot 43$
\end{tabular} & $\begin{array}{l}3 \cdot 46 \\
4 \cdot 59 \\
4 \cdot 25\end{array}$ & 2530 & $\begin{array}{c}\text { amp. 10-4 } \\
3.28 \\
3 \cdot 76 \\
4.25\end{array}$ & \begin{tabular}{|c|}
$\operatorname{amp} .10-\mathrm{i}$ \\
1.73 \\
$2 \cdot 55$ \\
3.26
\end{tabular} & $\begin{array}{l}1 \cdot 61 \\
1.80 \\
1.80\end{array}$ \\
\hline 1504 & $\begin{array}{l}2 \cdot 21 \\
250\end{array}$ & $\begin{array}{l}1 \cdot 495 \\
2 \cdot 15\end{array}$ & $\begin{array}{l}3 \cdot 05 \\
3 \cdot 44\end{array}$ & 2990 & $\begin{array}{l}2 \cdot 74 \\
3 \cdot 29 \\
3 \cdot 83\end{array}$ & $\begin{array}{l}1.24 \\
222 \\
3.41\end{array}$ & $\begin{array}{l}1 \cdot 62 \\
2 \cdot 05 \\
2 \cdot 32\end{array}$ \\
\hline 1725 & $\begin{array}{l}2 \cdot 54 \\
2 \cdot 88\end{array}$ & $\begin{array}{l}1 \cdot 87 \\
2 \cdot 44\end{array}$ & $\begin{array}{l}2 \cdot 90 \\
2: 45\end{array}$ & 3920 & $\begin{array}{l}2 \cdot 79 \\
3 \cdot 49\end{array}$ & $\begin{array}{l}0 \cdot 77 \\
2 \cdot 1\end{array}$ & $\begin{array}{l}0.99 \\
1.94\end{array}$ \\
\hline 2060 & $\begin{array}{l}266 \\
306 \\
3 \cdot 46\end{array}$ & $\begin{array}{l}1 \cdot 53 \\
2 \cdot 02 \\
2 \cdot 88\end{array}$ & $\begin{array}{l}2 \cdot 16 \\
2 \cdot 16 \\
2 \cdot 40\end{array}$ & 1400 & $\begin{array}{l}2 \cdot 34 \\
2 \cdot 61\end{array}$ & $\begin{array}{l}1 \cdot 64 \\
2 \cdot 32\end{array}$ & $\begin{array}{l}3.0 \\
3 \cdot 4\end{array}$ \\
\hline
\end{tabular}

Table XIII.

Cathodic Polarization. E.M.F. of small electrode $0 \cdot 13$ volt.

\begin{tabular}{|c|c|c|c|c|c|c|c|}
\hline Freq. & $\begin{array}{l}\text { Altern. } \\
\text { Current. }\end{array}$ & $\begin{array}{l}\text { Direct } \\
\text { Current. }\end{array}$ & $\frac{\mathrm{I}}{\overline{i_{0}^{2}}}$ & Freq. & $\begin{array}{c}\text { Altem. } \\
\text { Current. }\end{array}$ & $\begin{array}{l}\text { Direct } \\
\text { Ourrent. }\end{array}$ & $\frac{\mathrm{I}}{\bar{i}_{0}^{2}}$ \\
\hline 1380 & $\underset{2.88}{\operatorname{amp.} 10^{-4}}$ & $\underset{1.76}{\operatorname{amp.} 10^{-i}}$ & $2 \cdot 12$ & 3320 & $\begin{array}{c}\text { amp. } 10^{-4} \\
3.08 \\
3.67\end{array}$ & $\begin{array}{c}\operatorname{amp.10^{-7}} \\
1.29 \\
2.6\end{array}$ & $\begin{array}{l}1 \cdot 36 \\
1 \cdot 93\end{array}$ \\
\hline 1579 & $\begin{array}{l}298 \\
3: 30\end{array}$ & $\begin{array}{l}1 \cdot 75 \\
3 \cdot 13\end{array}$ & $\begin{array}{l}1.97 \\
2 \cdot 88\end{array}$ & & & & \\
\hline 1819 & $\begin{array}{l}3 \cdot 10 \\
3 \cdot 46\end{array}$ & $\begin{array}{l}1 \cdot 75 \\
2 \cdot 54\end{array}$ & $\begin{array}{l}1 \cdot 82 \\
2 \cdot 18\end{array}$ & 3620 & $\begin{array}{l}2 \cdot 64 \\
3 \cdot 32\end{array}$ & $\begin{array}{l}0.745 \\
1.885\end{array}$ & $\begin{array}{l}1.07 \\
1.70\end{array}$ \\
\hline 2320 & $\begin{array}{l}3 \cdot 03 \\
3 \cdot 47 \\
3 \cdot 93\end{array}$ & $\begin{array}{l}1.24 \\
2.34 \\
4.9\end{array}$ & $\begin{array}{l}1 \cdot 35 \\
1 \cdot 94 \\
3 \cdot 18\end{array}$ & 4160 & $\begin{array}{l}2 \cdot 96 \\
3 \cdot 74\end{array}$ & $\begin{array}{l}1 \cdot 115 \\
2 \cdot 75\end{array}$ & $\begin{array}{l}1 \cdot 27 \\
1 \cdot 97\end{array}$ \\
\hline 2780 & $\begin{array}{l}3 \cdot 12 \\
3 \cdot 68\end{array}$ & $\begin{array}{l}1 \cdot 21 \\
2 \cdot 22\end{array}$ & $\begin{array}{l}1 \cdot 24 \\
1 \cdot 69\end{array}$ & 1429 & $\begin{array}{l}2 \cdot 70 \\
2 \cdot 99\end{array}$ & $\begin{array}{l}1.071 \\
1.755\end{array}$ & $\begin{array}{l}1.47 \\
1.96\end{array}$ \\
\hline
\end{tabular}

It appears from these results, that it is only when the electrode is practically saturated with the respective gas that there is any approach to constancy of $\frac{\mathrm{I}}{i_{0}^{2}}$ for a given frequency, When the electrode is unsaturated, the direct current increases much faster than a quantity proportional to the square of the alternating current.

It is also to be seen that the diminution of the sensitiveness with increase of frequency is less than in the case of mercury. 
Summary.

To summarize the results obtained in this paper :-

(1) It is shown that a perfectly symmetrical alternating current acting at a polarizable electrode leads, according to the osmotic theory of polarization, to an asymmetry of the polarization-in other words to a direct current.

(2) The case of a mercury electrode being worked out gives as a result that the direct current $I$ satisfies the relation $\frac{\mathrm{NI}}{\overline{i_{0}^{2}}}=$ const., where $\mathrm{N}$ is the frequency and $i_{0} \sin 2 \pi \mathrm{N} t$ is the alternating current. The direction of the current corresponds with an effective diminution of the concentration in the neighbourhood of the electrode.

(3) The same relation should hold when the electrolyte is a solution of a complex salt, provided that diffusion from and to the layer of electrolyte surrounding the electrode plays the important part in the polarization.

(4) In cases, however, where the polarization arises (as described by Krïger) from the finiteness of the velocity of reaction by which mercury ions are supplied from the complex molecules, the relation $\frac{\mathrm{I}}{i_{0}^{2}}=$ const. holds, being inde-
pendent of the frequency.

(5) A disturbing effect which masks, in many cases, the above described one is accounted for, and the reasons assigned why in certi in cases this disturbing effect is absent, or nearly so.

(6) Experiments, made with KCN solution, show to what extent $\frac{\mathrm{NI}}{i_{0}^{2}}=$ const. is found to hold at high frequencies. At low frequencies the relation is totally departed from, and there appears to exist a critical frequency where a sudden change in the phenomenon takes place.

(7) An application to the "electrolytic coherer" is suggested on the supposition that the equilibrium in some reaction such as $\mathrm{H}_{2}=2 \mathrm{H}$ is reached with finite velocity, and an effect corresponding with (4) above takes place.

(8) Experiments with a Pt electrode, both anodically and cathodically polarized, show that the magnitude of the directcurrent effect varies at higher frequencies much less with the frequency than is the case with the mercury electrode.

The above work was done in the Institute for Physical Chemistry of the University of Göttingen; and I bave the pleasant duty of thanking Prof. Nernst and Dr. Krüger for placing the facilities at my disposal and for much helpful interest and advice during the work. 